\title{
Measuring the Unmeasurable: Comparative Assessment of Urban Vulnerability for Coastal Megacities - New York, London, Tokyo, Kolkata and Lagos
}

\author{
Torsten Welle* and Joern Birkmann \\ Institute of Spatial and Regional Planning, \\ University of Stuttgart, Germany \\ *torsten.welle@ireus.uni-stuttgart.de
}

Published 30 March 2017

\begin{abstract}
The following paper presents an approach to measure the vulnerability of urban megacities with a comparative approach across cities in the Global North and South. The assessment of city vulnerability is key in order to inform risk management and adaptation strategies that are needed to build resilience against extreme events, natural hazards or consequences of climate change. While the New Urban Agenda (UN Habitat 2016) underscores the necessity for inclusive, sustainable and resilient urban development, the findings of the vulnerability assessment in the five selected coastal megacities that were part of the TRUC project - Kolkata, Lagos, London, New York and Tokyo - show that next to resource deficiencies and poverty, issues of governance also need to be addressed if we really aim to increase the coping capacities of urban population to deal with extreme events and natural hazards. While this is a major challenge for the selected coastal megacities in the Global South, the analysis reveals that in terms of adaptive capacities also, megacities in the Global North, such as New York and London, face major challenges and rank nearly on a similar level as Kolkata. Even though such assessments provide only a first overview, it is evident that effective risk management approaches and positive transformative change that can include long-term as well as immediate risk management concerns will not only require improvements at the local level but also significant changes in sub-national and national context conditions. This is particularly true in terms of fighting corruption and
\end{abstract}

This is an Open Access article published by World Scientific Publishing Company. It is distributed under the terms of the Creative Commons Attribution 4.0 (CC-BY) License. Further distribution of this work is permitted, provided the original work is properly cited. 
increasing the reliability and trustworthiness of local and national institutions and their regulations.

Keywords: Comparative vulnerability assessment; coastal megacities; transformation; resilience.

\section{Introduction}

Measuring and assessing vulnerability and resilience of cities and urban communities as well as urbanization trends is important for informed decision making in terms of risk management and adaptation (see e.g., Birkmann 2013; Balica et al. 2012, Suarez et al. 2016, Garschagen and Romero-Lankao 2015; Rosenzweig et al. 2016). Most approaches to address risk management are often solely informed by hazard maps and hazard assessments. However, hazards and extreme events can only trigger disasters and lead to high levels of risks if the exposed city or community is also vulnerable. Therefore, the assessment of urban vulnerability is key in order to understand core components of risk. Vulnerability assessment is a prerequisite for informed decision making in risk management, particularly for politicians and local households that live in cities that have experienced or might experience extreme events and environmental change. The paper can be seen as a contribution to the UN-Habitat Global Urban Indicators initiative that started in 1991 aiming at monitoring urban conditions worldwide. The initiative also focuses on key issues of the UN-Habitat Agenda and the Millennium Development Goals (see in detail UN Habitat (2009)). Also, the New Urban Agenda agreed upon in Quito this year (2016) calls for inclusive, sustainable and resilient urban development. Against this background, the following paper contributes to a better understanding and monitoring of the vulnerability of entire cities to natural hazards and climate change using freely available data. In this regard, the paper develops an approach for selected coastal megacities in the Global South and North to assess vulnerability at city level using data, which allows monitoring and comparing those cities. The selection of cities was predefined through the Transformation of Urban Coasts (TRUC) project, which included coastal megacities from the Global North and South, namely Lagos, Kolkata, Tokyo, London and New York. All these coastal megacities are likely to face adverse consequences due to climate change such as more intensive heat waves or floods in the future. The research was conducted within the project TRUC that at its heart aimed at integrating biophysical and social science approaches in vulnerability and risk assessment. 


\subsection{The city resilience index system}

Measuring vulnerability and resilience at the city scale is an important issue that received increasing attention in recent years. For example, the Rockefeller Foundation in cooperation with ARUP has developed and published a City Resilience Index in order to understand and measure city resilience. The semi-quantitative assessment approach is based on a list of 52 indicators grouped along 12 critical functions of a resilient city. Core themes covered within the City Resilience Index framework encompass issues of health and wellbeing, economy and society, infrastructure and ecosystems as well as leadership and strategy (see e.g., ARUP 2014).

Each indicator is classified and evaluated along seven qualities of a resilient system providing a scale of relevance of each quality to each indicator. Based on this conceptual framework, city assessors or representatives of each city assign scores - 1-5 linear scale - for worst and best performances within each indicator. The qualitative resilience profile combines the goals of the index with the average of the assigned scores. This means the quantitative resilience profile combines the index goals with a normalized quantitative metric data based on semi-quantitative and qualitative judgements by local experts. While the critical functions of a city in the context of resilience and the respective indicators were derived by a literature analysis and stakeholder discussions (see Arup 2014), the assessment and calculation of each indicator was conducted in close collaboration with representatives of the cities selected. Hence, local experts assign quantitative scores for the different indicators and subjects identified before. The data collection and analysis is conducted through a web-based platform that is used by the city government and their partners and allows the monitoring of city performance over time. In this regard, the City Resilience Assessment methodology is based on stakeholders' perceptions rather than on statistical data alone. The approach allows a relatively high number of indicators that can encompass a detailed resilience profile, however, the subjective judgements by local experts also heavily influence the scores. For example, the self-evaluation of the leadership and management capacity of municipal governments might lead to results that reflect positively on their own performance. However, the authors of the Resilience Index argue that the methodology is not primarily designed for comparative analysis between cities but is rather intended to measure progress over time.

\section{Assessing the Vulnerability of Coastal Megacities: Data and Methodological Approach}

Compared to the City Resilience Index and Indicator approach, the methodology of the City Vulnerability Index for coastal megacities is based on quantitative 
indicators based on statistical data. This means local, national or international data banks were used to calculate different indicators along core components and characteristics of city vulnerability (see Figure 1). In cases where data were not available for a specific indicator, as it was the case in Lagos, we used expert judgements and comparisons between cities to derive values. However, a common characteristic of all cities is that they are megacities which have experienced natural hazards in the past and are exposed to future impacts of climate change that most likely modify stressors like heat stress or flood patterns as well as sea level rise. In addition, these cities contain different quarters with differential socioeconomic and demographic profiles that also imply different levels of vulnerability. In contrast to a risk assessment that also includes the physical hazard, the vulnerability assessment captured the societal component of risk. Hence, we explored the different capacities and fragilities of cities and urban population that might be exposed to natural hazards. This means the assessment shifted the focus from the assessment of extreme events and hazards towards the improved understanding of societal conditions that make people more likely to experience harm and to suffer losses - independent of a specific natural hazard. In this regard, the methodological approach for assessing vulnerability is based on an indicator system that differentiates vulnerability along three sub-components: susceptibility, coping capacities and adaptive capacities. While susceptibility aims to characterize fragilities of people and precarious living conditions in cities depending on aspects of poverty, the access to basic infrastructure services or the housing situation, the subcomponents of coping and adaptation examine response capacities of people and institutions to deal with extreme events and natural hazards in the short and longrun. Coping capacities in urban areas depend, for example, on the governance conditions in cities and city quarters, for example, high levels of corruption or crime are rather indicators for limited coping capacities compared to urban areas where low crime rates and little corruption exist. Crime and corruption can also undermine state authorities that are essential when aiming to promote early warning systems to extreme events. Coping capacities are in our approach seen as capacities that help people to deal with the immediate impacts of extreme events and therefore, the quantity and quality of medical services and disaster response units - such as fire brigades - do matter. In contrast, adaptive capacities aim to explore resources and capacities of people to adapt to environmental change in the medium and long run. Issues of education and environmental qualities as well as gender issues are part of this sub-component. Also, aspects of green transportation facilities such as public transport network and human behavior in terms of waste generation were included to picture the adaptive capacities of a city. Due to the limited data, the catalogue of wanted variables and indicators had to be reduced to 
the number of accessible and measureable parameters, for example, insurance data, which is an important aspect for coping could not be gathered in the cities. Or indicators that represent early warning capacities were not available and could not be integrated into the final list of indicators. Moreover, there are linkages between susceptibility, coping and adaptation. Susceptibility, for example, poverty and a high unemployment rate can restrict the development of coping and adaptive capacities. Also, people that live under endemic corruption might not be able to invest in education and governmental funds for education are constrained by high levels of corruption at national scale.

Overall, the methodology of the city vulnerability assessment is based on the methodology of the World Risk Index developed by Birkmann and Welle (see Birkmann et al. 2011; Welle and Birkmann 2015, 2016). The city vulnerability assessment is a modified version of this, focusing particularly on urban areas and on vulnerability only. The indicator approach is based on a modular concept focusing on susceptibility, coping and adaptive capacities of people and organizations in these cities. Figure 1 shows the different indicators used to assess urban vulnerability with comparative data and parameters. The selection process of relevant indicators was also based in the first phase on a literature analysis in order to identify important components and characteristics of urban vulnerability in megacities for the predefined sub-components of vulnerability. In addition, the indicator list was discussed with experts within the TRUC project and in workshops with stakeholders, for example, in Lagos and London. Consequently, the selection and discussion of the appropriateness of the indicators is based on an iterative process that involved the teams of researchers from each city location as well as practitioners that were asked to comment on the indicators, for example, in workshops.

Beside the general relevance of the indicator for the respective indicandum (urban vulnerability in coastal megacities), another important requirement was the availability of comparative data for the respective indicators for the selected five megacities and the open access to the data. The data should be available at the city sub-district level or below. These requirements restricted the use of idiosyncratic indicators that might have been interesting and valid for one city, but that could not be applied for the comparative analysis.

According to the method of the World Risk Index (Welle and Birkmann 2015; Birkmann et al. 2016), we categorized susceptibility into five sub-components such as demography, health and nutrition, poverty and income, economic capacity and income distribution as well as housing and neighbourhood conditions. Indicators such as the percentage of people older than 65 years, poverty rate within a city, the distribution of wealth (Gini Index) and the share of population living in 


\section{Susceptibility}

$$
\begin{aligned}
= & \frac{1}{5} *\left(\frac{1}{2} *(A+B)\right)+\frac{1}{5} *\left(\frac{1}{3} *(C+D+E)\right)+\frac{1}{5} *\left(\frac{1}{3} *(F+G+H)\right)+\frac{1}{5} *\left(\frac{1}{2} *(I+J)\right) \\
& +\frac{1}{5} * K
\end{aligned}
$$

\section{Lack of Coping Capacity}

$$
=100-\left(\frac{1}{4} *\left(\frac{1}{3} *(A+B+C)\right)\right)+\left(\frac{1}{4} *\left(\frac{1}{2} *(D+E)\right)\right)+\left(\frac{1}{4} * F\right)+\left(\frac{1}{4} * G\right)
$$

\section{Lack of Adaptive Capacity}

$$
\begin{aligned}
= & 100-\left(\frac{1}{4} *\left(\frac{1}{2} *(A+B)\right)\right)+\left(\frac{1}{4} *\left(\frac{1}{2} *(C+D)\right)\right)+\left(\frac{1}{4} *\left(\frac{1}{2} *(E+F)\right)\right) \\
& +\left(\frac{1}{4} *\left(\frac{1}{2} *(G+H)\right)\right) \\
& \times\left(\frac{1}{5} *\left(\frac{1}{2} *(A+B)\right)\right)+\left(\frac{1}{5} *\left(\frac{1}{3} *(C+D+E)\right)\right)+\left(\frac{1}{5} *\left(\frac{1}{3} *(F+G+G)\right)\right) \\
& +\left(\frac{1}{5} *\left(\frac{1}{2} *(I+J)\right)\right)+\left(\frac{1}{5} * K\right)
\end{aligned}
$$

Equation 1: The abbreviations refer to the abbreviations within susceptibility, coping capacity and adaptive capacity in Figure 1

Component: Susceptibility

\begin{tabular}{|l|l|l|}
\hline \multicolumn{1}{|c|}{ Indicator } & \multicolumn{1}{|c|}{ Name } & \multicolumn{1}{c|}{ Source } \\
\hline A & Population density (person/ $/ \mathrm{km}^{2}$ ) & $\begin{array}{l}\text { National statistical agencies/statistical office of } \\
\text { the cities (census bureaus) }\end{array}$ \\
\hline B & $\begin{array}{l}\text { Proportion of population aged } 65 \text { and } \\
\text { over }\end{array}$ & $\begin{array}{l}\text { National statistical agencies/statistical office of } \\
\text { the cities (census bureaus) }\end{array}$ \\
\hline C & Life expectancy & $\begin{array}{l}\text { National statistical agencies/statistical office of } \\
\text { the cities (census bureaus) }\end{array}$ \\
\hline D & $\begin{array}{l}\text { Percentage of obese population } \\
\text { (malnutrition) }\end{array}$ & $\begin{array}{l}\text { OECD Statistical Portal and statistical office of the } \\
\text { cities (census bureaus) }\end{array}$ \\
\hline E & Infant mortality rate & Global City Indicators (World City data) \\
\hline F & Dependency ratio & (HDR 2013) World Bank development indicators \\
\hline G & $\begin{array}{l}\text { Unemployment rate } \\
\text { Knoema Atlas }\end{array}$ \\
\hline H & Poverty rate & $\begin{array}{l}\text { Global City Indicators (World City data) and } \\
\text { statistical office of the cities (census bureaus) }\end{array}$ \\
\hline I & GDP per capita in US \$(PPP) & Global City Indicators (World City data) \\
\hline J & Gini Index & UN-HABITAT, Global Urban Observatory \\
\hline K & $\begin{array}{l}\text { Overcrowded apartments and slum } \\
\text { population }\end{array}$ & statistical office of the cities (census bureaus) \\
\hline
\end{tabular}

Figure 1. Overview of the Indicators and Data Sources Used to Assess Urban Vulnerability in the Five Coastal Megacities 
Measuring the Unmeasurable: Comparative Assessment of Urban Vulnerability for Coastal Megacities

Component: Coping Capacity

\begin{tabular}{|l|l|l|}
\hline \multicolumn{1}{|c|}{ Indicator } & \multicolumn{1}{|c|}{ Name } & \multicolumn{1}{|c|}{ Source } \\
\hline A & $\begin{array}{l}\text { Corruption Perception Index (country } \\
\text { scale) }\end{array}$ & Transperancy International \\
\hline B & Crime Index & Numbeo \\
\hline C & $\begin{array}{l}\text { Urban planning (green space per person } \\
\mathrm{m}^{2} / \text { person) }\end{array}$ & Green City Index \\
\hline D & $\begin{array}{l}\text { Number of physicians per 100,000 } \\
\text { People }\end{array}$ & $\begin{array}{l}\text { Global City Indicators (World City data) and } \\
\text { statistical office of the cities (health department) }\end{array}$ \\
\hline E & $\begin{array}{l}\text { Number of hospitals beds per 100,000 } \\
\text { people }\end{array}$ & $\begin{array}{l}\text { Global City Indicators (World City data and } \\
\text { statistical office of the cities (health department) }\end{array}$ \\
\hline F & $\begin{array}{l}\text { GDP of the metropolitan area as } \% \text { of } \\
\text { national value }\end{array}$ & $\begin{array}{l}\text { (OECD Statistical Portal and statistical office of } \\
\text { the cities) }\end{array}$ \\
\hline G & $\begin{array}{l}\text { Number of fire fighters/ per 100,000 } \\
\text { people }\end{array}$ & \begin{tabular}{l} 
Statistical office of the cities (fire departments) \\
\hline
\end{tabular} \\
\hline
\end{tabular}

\section{Component: Adaptive Capacity}

\begin{tabular}{|l|l|l|}
\hline \multicolumn{1}{|c|}{ Indicator } & \multicolumn{1}{|c|}{ Name } & \multicolumn{1}{c|}{ Source } \\
\hline A & $\begin{array}{l}\text { Percent of population with higher } \\
\text { education (students completing } \\
\text { secondary education) }\end{array}$ & $\begin{array}{l}\text { Statistical office of the cities (education } \\
\text { department) national education reports }\end{array}$ \\
\hline B & Literacy rates & $\begin{array}{l}\text { Statistical office of the cities (education } \\
\text { department) (London: national country statistics) }\end{array}$ \\
\hline C & Air quality (PM10) $\mu \mathrm{g} / \mathrm{m} 3$ & WHO data city indicators 2011 \\
\hline D & $\begin{array}{l}\text { Waste generated by person } \\
\text { (kg/person/year) }\end{array}$ & Green City Index \\
\hline E & $\begin{array}{l}\text { Share of female representatives in the } \\
\text { National Parliament (sub index) }\end{array}$ & World Bank indicator (national scale) \\
\hline F & $\begin{array}{l}\text { Share of women in wage employment in } \\
\text { the non-agricultural sector (\% of total } \\
\text { non-agricultural employment) }\end{array}$ & World Bank indicator (national scale) \\
\hline G & $\begin{array}{l}\text { GHG emissions per cap.of 50 largest } \\
\text { cities ratio of case study cities }\end{array}$ & World Bank: Cities and Climate Change Report \\
\hline H & $\begin{array}{l}\text { Transport system (public transport } \\
\text { network km/km2) }\end{array}$ & Green City Index \\
\hline
\end{tabular}

slums or overcrowded housing conditions (e.g., apartments) were categorized under those sub-components and used to assess different aspects of susceptibility of the five selected megacities. The individual indicators are derived from various data sources such as national statistical agencies (census bureaus), the OECD statistical portal and statistical office for cities, the Global City Indicators as well as from the Global Urban Observatory (see detailed list in Figure 1).

Coping capacity was also differentiated into five sub-components, but due to lack of respective data, we chose to use four sub-components. The first is government and authorities, followed by medical services, economic coverage and 
disaster preparedness. Although the requirement was to use only data at city scale level, we decided to also integrate data with a national scale resolution such as the Corruption Perception Index since no data that represent governance were available at city level. Thus, corruption levels as well as city crime rates were used as proxies to provide information about the governance context and quality of urban management, since they represent key factors of vulnerability (Welle and Birkmann 2015) and we argue that national governance conditions (corruption, state failure, etc.) also heavily influence urban development and respective coping capacities at city level. Indicators to assess medical services and disaster preparedness, such as the number of hospital beds per 100,000 people or the number of fire fighters per 100,000 inhabitants, were used as proxies to characterize capacities to deal with the direct consequences of extreme weather events or natural hazards.

The adaptive capacity was divided into education and research, environmental status/ecosystem protection, gender equity and adaptation strategies/awareness sub-components. Indicators to measure the capacities of urban population to adapt to environmental change and extreme events in the medium and long run encompassed aspects such as the educational level of the urban population and the literacy rate. In addition, we also focused on issues of the environment qualities in cities, represented by issues of air quality and waste generated by person. According to the Corruption Perception Index, we also used global data to assess aspects of gender equity. Thus, the share of female representatives in the National Parliament and the share of women in wage employment in the non-agricultural sector were integrated as proxies for gender aspects. Greenhouse Gas (GHG) emissions per capita and the public transport network are used as proxies for adaptation strategies and awareness towards climate change. Data were derived, e.g., from WHO data city indicators, Green City Index and reports from the World Bank (Cities and Climate Change Report) (see Figure 1).

While comparative data on issues of susceptibility, particularly poverty, life expectancy, etc. are available, data on coping and adaptive capacities were much more scarce. Even though these two sub-components (coping and adaptation) of vulnerability are key when talking about changing risk management strategies and transformation, only few data could be found that particularly capture early warning capacities or lessons learned after extreme events and disasters.

The individual indicators that do not have per cent values were transformed into values between 0 and 100 using min max transformation. We focus on per cent values without transforming, since we want to keep the original information, which reflects the original situation and does distort the data range artificially; additionally, keeping the original data is easier to understand for decision makers and practitioners. With respect to the min max transformation, we use maximum and 
minimum values that occur in the databases, for example population density, none of our five study cities has the highest population density in the world, the highest value worldwide is noted for Mumbai in India and the lowest is Hickory in the USA. Following formulas show the calculation of the three vulnerability components (Eqs. (1)-(3)):

Afterwards, the susceptibility index, the lack of coping capacity index and the lack of adaptive capacity index were weighted equally and aggregated to the vulnerability index (detailed descriptions of the method are presented in Welle and Birkmann 2015).

\section{Discussion of Results}

The analysis of the results generated by the city vulnerability assessment underscores that in terms of susceptibility, the city of Lagos ranks significantly higher than all other coastal megacities assessed, which is caused by low life expectancy and the highest infant mortality rate of all five cities as well as the highest poverty rate of 48.6 percent. Interestingly, Kolkata has a significantly lower susceptibility value (below 40 percent points) compared to Lagos (with nearly 50 percent points) which can be explained due to a rate of slum population half as high: 31 percent in Kolkata and 64.2 percent in Lagos. Another reason is the income distribution. In Kolkata, the Gini Index is 0.38 compared to 0.64 in Lagos, which is close to 1 , representing very high income disparity. In addition, the susceptibility values between London, New York and Tokyo only differ slightly.

In contrast, the index results of the lack of coping capacities show that major differences exist between the coping capacities of the coastal megacities in the Global South versus the Global North. Lagos and Kolkata have not only fewer resources to cope but also operate in context conditions where corruption and crime are rather high. For example, the corruption value is quite low in both cities — Kolkata 38 and Lagos 27 out of 100 — where lower values represent high corruption. The biggest difference between the cities of the Global North and the Global South could be derived from the number of physicians per 100,000 people, which is more than five times lower. The number of fire fighters per 100,000, which is a proxy for disaster preparedness, is very low in Kolkata (27.7) and Lagos (6.5) compared to the highest value of Tokyo (42.7).

Interestingly, the assessment of the lack of adaptive capacities between the five coastal megacities reveals that major differences can be found between Tokyo and all other cities. New York ranks in terms of the lack of adaptive capacities nearly similar as Kolkata, which is surprising. While the education and education indicators, such as the percentage of population with higher education (students 


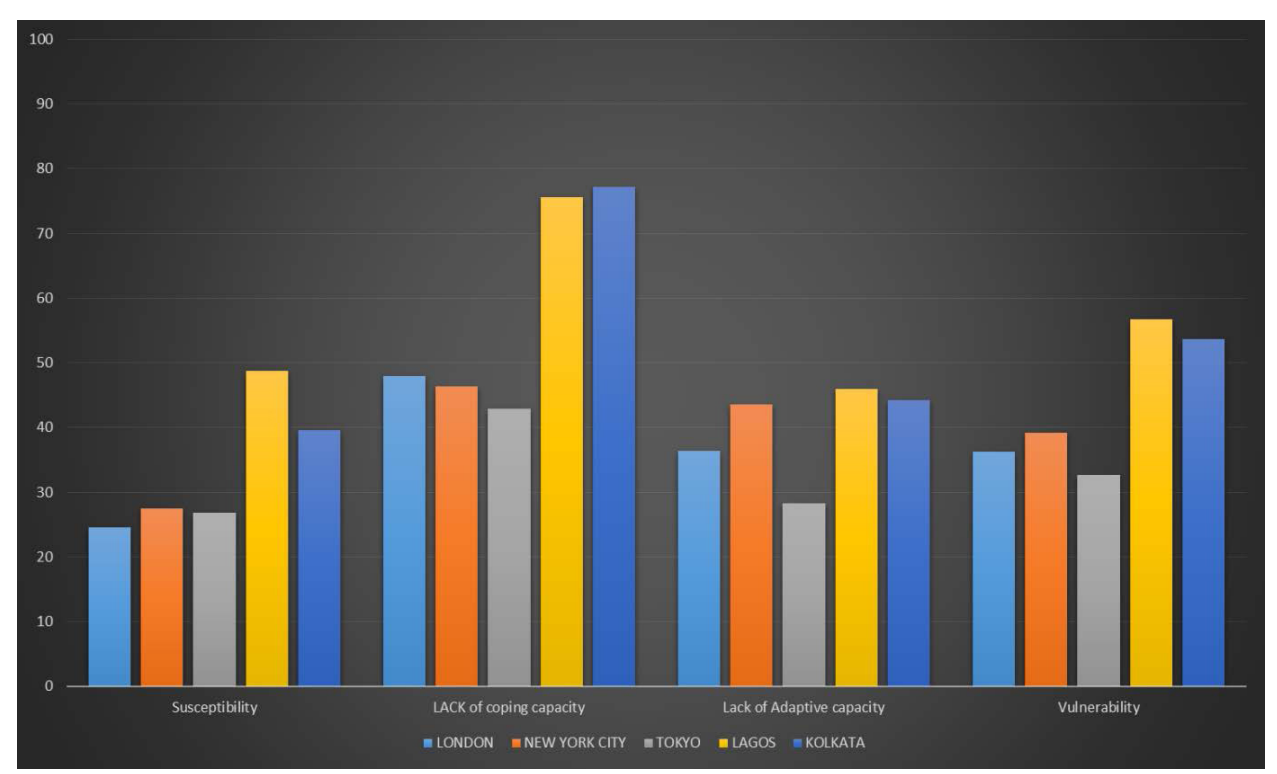

Figure 2. Results of the Vulnerability Assessment in Five Selected Coastal Megacities Source: Author's figure.

completing secondary education) and also the literacy rate, are much higher in New York compared to Lagos and Kolkata, it is interesting to note that the performance of New York in terms of the environmental status and ecosystem protection, for example, in terms of waste generated per person and also the GHG emissions (in the category adaptation), is rather low. In addition, it is noteworthy that the comparison of New York with London and Tokyo as coastal megacities in the Global North also reveals significant differences in the category of education and research. While Tokyo and London show literacy rates of about 99\%, meaning that nearly all people can read and write, the same indicator shows for New York a value of $80 \%$. Thus, about $20 \%$ of the population there can neither read nor write.

Overall, it is interesting that even though Tokyo has many elderly inhabitants and is frequently exposed to extreme events, it is - in the comparative analysis the coastal megacity with the lowest city vulnerability. Highest city vulnerabilities can be found in Lagos and Kolkata (see Figure 2).

\section{Interpretation, Challenges and Conclusions}

Even though the individual indicators might encompass some uncertainty in terms of the absolute value, the results and the significant differences between the cities underscore that major development differences still exist between coastal 
megacities in the Global North versus the Global South. This is not surprising, however, it is interesting to note that these development differences are especially true to the overall vulnerability and the sub-components of susceptibility and the lack of coping capacities. Interestingly, the assessment of the lack of adaptive capacities shows a different picture in terms of the North-South gap. This means if one also considers environmental resource efficiencies and environmental pollution as major issues that hamper or limit adaptive capacities, the differences between, for example, the megacities New York and Tokyo are increasing. While, for example, the waste generated per capita in New York is about $560 \mathrm{~kg}$ per year, it is about $400 \mathrm{~kg}$ per year per person in Tokyo. Similarly, the PM10 concentration fine particles - indicates a significantly higher air pollution in New York compared to Tokyo. This leads to the fact that the performance of New York in terms of the lack of adaptive capacities is nearly on a similar level like Kolkata, even though the reasons of this lower performance are quite different between the two cities.

The assessment of vulnerability and especially the comparison of the subcomponents also lead to further conclusions. The most severe differences can be found in terms of the lack of coping capacities. Lagos and Kolkata have fewer resources for developing medical services and corruption and crime is significantly higher in these two cities compared to London, New York and Tokyo. For example, the crime index 2015 that ranks very safe cities or cities with no crime with 100 and very high crime rates with 0 shows for Tokyo a value of about 22, for New York, London and Kolkata a value of about 48-50 and for Lagos a value of 74 . Also, the corruption perception index for these cities or countries underscores major differences and coping challenges. The scale of the corruption perception index is reverse, meaning that 100 points are places with the lowest corruption and 0 indicates total corruption. While London, Tokyo and New York rank about 74-78 index points, Kolkata shows a value of about 38 and Lagos of about 27. Consequently, promoting positive transformative change and resilience building cannot solely be achieved by better funding and more financial resource, but requires in parallel changes and improvements in governance conditions at local and national levels. Solely if these governance challenges are considered, effective and inclusive governance can grow and develop (see also Rosenzweig et al. 2016). We can conclude that conventional urban planning instruments that might work in the Global North will most likely not be sufficient in steering urban development in the Global South due to high levels of informality and an already large part of the population living in informal settlements. However, effective leadership and trust in local authorities as well as the encouragement of individuals to take action in building resilience is hindered if high levels of corruption and crime hamper the development of institutions, organizations and even physical infrastructures 
(see also Birkmann et al. 2016). Approaches of inclusive and integrative (crosssectoral) planning will fail if people do not believe in state or local organizations, their legitimacy and if respective regulations or planning systems are bypassed by economically powerful or disadvantaged population groups (see Birkmann et al. 2014). This means that approaches to reduce vulnerability and to increase resilience and transformative change are not only challenged by resource deficiencies and socio-economic or demographic conditions at the local level, but at the same time, also instability and fragility at the city as well as national levels significantly influence the lack of coping capacities of local people.

In this regard, urban adaptation strategies and respective funding structures that are primarily designed for the city scale need to explore how next to local level activities, national context conditions can also be addressed within these programmes. It is likely that improvements at the local level are undermined if national influences and regulations are not modified at the same time to support local adaptation. Hence, a pure focus on the individual city might be misleading when aiming to improve the coping capacities of cities that are hampered by high level of corruption. These limitations and constraints of current urban adaptation programmes and linkages between city and national scale vulnerability patterns and influences should receive a higher attention in order to ensure that pilot projects at the city level can be made more sustainable in the medium and long run.

Next to these thematic issues, methodological challenges also still exist. The data available for measuring coping and adaptive capacities of coastal megacities are quite rare. Even in times of big data and new open data sources, data particularly regarding different response capacities - are not sufficiently systematized and available. Also, lessons learned are often not documented. Therefore, we still lack information for these important themes for studies across the cities. Consequently, additional methodologies and strategies need to be developed and applied in order to capture differential coping and adaptation processes of people in a comparative way.

For example, the timeliness of the data available for cities is an issue if we aim to examine changes in vulnerability at the city level. Interviews at the local level, for example, with local governmental institutions and even ministries in Lagos, revealed that various stakeholders are not aware of the availability of data in some international reports and monitoring tools. Consequently, another recommendation is to better inform local people about the availability of data and international comparative data through new technologies such as mobile phones. Short comparative information about the life expectancy of urban population, the percentage of obese or the infant mortality rate for selected megacities in the Global South or Global North could help better understanding of the challenges these cities are 
facing. The present discourse about risks facing megacities is often dominated by a highly technological driven understanding of urban development under the heading of the so-called "smart cities". However, understanding progress in such megacities also requires - next to the measurement of own performance indicators - an improved understanding of what other megacities look like.

\section{Acknowledgments}

Research reported in this paper was undertaken as part of the Belmont Forum funded Transformation and Resilience on Urban Coasts (TRUC) project. This project was supported by Japan Society for the Promotion of Science, the UK Natural Environment Research Council and Economic and Social Research Council (NE/L008971/1), the German Research Foundation (GZ: BI 1655/1-1), The Ministry of Earth Sciences, Government of India (MoES/01-CZM/Truc/2013) and US National Science Foundation (1342966).

\section{References}

ARUP International Development and The Rockefeller Foundation (2014). City Resilience Index: Understanding and measuring city resilience, London.

Balica, SF, Wright NG and van der Meulen F (2012). A flood vulnerability index for coastal cities and its use in assessing climate change impacts. Natural Hazards, 64: 73-105.

Birkmann J, Welle T, Krause D, Wolfertz J, Suarez DC and Setiadi N (2011). WorldRiskIndex: Concept and Results. In: WorldRiskReport 2011, Alliance Development Works (eds.), Berlin, pp. 13-42.

Birkmann, Joern (ed.) (2013). Measuring Vulnerability to Natural Hazards: Towards Disaster Resilient Societies, Tokyo, Second Editon, New York, Paris United Nations University Press.

Birkmann, J and Welle T (2015). Assessing the risk of loss and damage: Exposure, vulnerability and risk to climate related hazards for different country classifications. International Journal of Global Warming, 8(2): 191-212.

Birkmann, J and Welle T (2016). The WorldRisikIndex 2016-Reveals the necessity for regional cooperation in vulnerability reduction. Journal of Extreme Events, 3(1): 1650005. DOI: 10.1142/S2345737616500056.

Birkmann, J, Garschagen M and Setiadi N (2014). New challenges for adaptive urban governance in highly dynamic environments: Revisiting planning systems and tools for adaptive and strategic planning. Urban Climate, 7: 115-133.

Birkmann, J, Welle T, Solecki W, Lwasa S and Garschagen M (2016). Boost resilience of small and mid-sized cities - smaller settlements are growing faster than megacities — and they need more protection from extreme events. Nature, 537: 605-608.

Garschagen, M and Romero-Lankao, P (2015). Exploring the relationships between urbanization trends and climate change vulnerability. Climatic Change, 133(1): 37-52. 
Suárez, M, Gómez-Baggethun E, Benayas J and Tilbury D (2016). Towards an urban resilience index: A case study in 50 spanish cities, sustainability 2016. 8: 774, doi:10.3390/su8080774.

Rosenzweig, C et al. (2016). Climate Change and Cities: Second Assessment Report of the Urban Climate Change Research Network. Cambridge University Press.

UN Habitat (2016). The New Urban Agenda, Quito.

UN Habitat (2009). Urban Indicators Guideline. "Better information, better cities”. http:// mirror.unhabitat.org/downloads/docs/Urban_Indicators.pdf.

Welle, T and Birkmann J (2015). The world risk index - An approach to assess risk and vulnerability on a global scale. Journal of Extreme Events, 2(1): 1550003. DOI: 10.1142/S2345737615500037. 